Document downloaded from:

http://hdl.handle.net/10251/81806

This paper must be cited as:

Arias Carrascal, KS.; Climent Olmedo, MJ.; Corma Canós, A.; Iborra Chornet, S. (2016). Chemicals from Biomass: Synthesis of biologically active furanochalcones by ClaisenSchmidt condensation of biomass-derived 5-hydroxymethylfurfural (HMF) with acetophenones. Topics in Catalysis. 59(13):1257-1265. doi:10.1007/s11244-016-0646-3.

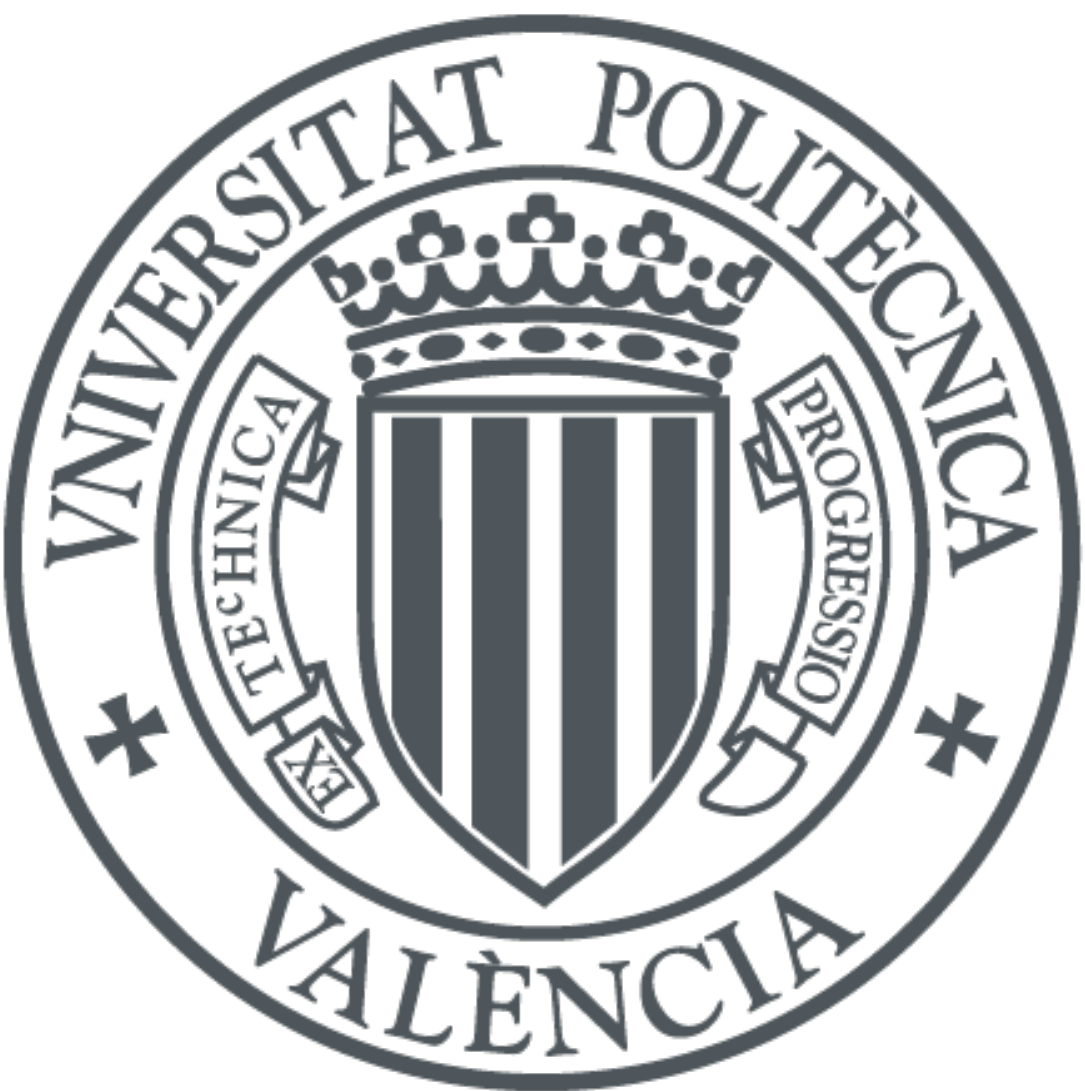

The final publication is available at

http://doi.org/10.1007/s11244-016-0646-3

Copyright Springer Verlag (Germany)

Additional Information 


\title{
Chemicals from Biomass: Synthesis of biologically active furanochalcones by Claisen-Schmidt condensation of biomass-derived 5-hydroxymethylfurfural (HMF) with acetophenones
}

\author{
Karen S. Arias, Maria J. Climent ${ }^{*}$, Avelino Corma,* Sara Iborra \\ Instituto de Tecnología Química (UPV-CSIC) \\ Universitat Politécnica de València \\ Avda dels Tarongers s/n, 46022, Valencia (Spain) \\ Fax: $(+34) 963877809$ \\ E-mail: acorma@itq.upv.es \\ mjcliol@qim.upv.es
}

\begin{abstract}
Furanochalcones have been synthesized trough the Claisen-Schmidt condensation of acetophenones and 5-hydroxymethylfurfural (HMF) using different solid base catalysts such as $\mathrm{MgO}, \mathrm{Al} / \mathrm{Mg}$ mixed oxide ( $\mathrm{HTc}$ ) with Lewis basic sites, and a hydrated $\mathrm{Al} / \mathrm{Mg}$ mixed oxide (HTr) with Bronsted basic sites. The three catalysts provide high selectivity in absence of solvent or in the presence of polar solvents such as ethanol or acetonitrile, however catalysts become rapidly deactivated due to the strong adsorption of $\mathrm{HMF}$ and the furanochalcone obtained on the catalyst surface. A further increase in solvent polarity by using a mixture ethanol-water allows obtaining high conversion and high selectivity to furanochalcone using $\mathrm{HTc}$ and $\mathrm{HTr}$ as catalysts. However, $\mathrm{MgO}$ becomes rapidly deactivated which was mainly attributed to structural changes on $\mathrm{MgO}$ that is in situ rehydrated into $\mathrm{Mg}(\mathrm{OH})_{2}$ with low activity for aldol condensations. When the reaction was performed using the homogeneous $\mathrm{NaOH}$ catalyst, it was found that their activity is higher than that of the solid catalyst, but the selectivity of the later is
\end{abstract}


clearly better. The results indicate that the active phase of the $\mathrm{Al} / \mathrm{Mg}$ mixed oxide (HTc) in the ethanol-water medium corresponds to a partially restored hydrotalcite with basic hydroxyl groups. The HTc sample could be applied to the synthesis of a variety of furanochalcones with excellent success, while the catalyst could be reused several reaction cycles without loss of activity.

KEYWORDS: chemicals from biomass, 5-hydroxymethylfurfural, Claisen-Schmidt condensation, furanochalcones, $\mathrm{MgO}, \mathrm{Al} / \mathrm{Mg}$ mixed oxides.

\section{INTRODUCTION}

In recent years extensive work has been done to maximize the sustainable utilization of biomass feedstocks while minimizing the $\mathrm{CO}_{2}$ emissions and avoiding competition with human and animal food. It is therefore desirable to obtain chemical products and liquid biofuels from lignocellulose biomass which does not compete with food production. The most interesting approximation to convert lignocelluloses biomass into valuable chemicals is through the utilization of the platform molecules produced from biomass by enzymatic and chemical processes [1]. Platform molecules such as lactic acid, levulinic acid, furfural, 5-hydroxymethyl furfural, $\gamma$-valerolactone, succinic acid etc, are highly functionalized molecules which can be converted in some cases with minimal derivatization in new materials, polymers and pharmaceuticals [2].Among them, furans derived from biomass such as furfural and 5-hydroxymethylfurfural (HMF) obtained by dehydration of pentoses and hexoses respectively, are versatile molecules that have increasingly attracted the attention as starting materials for the production of a variety of valuable compounds [3]. 
On the other hand, chalcones with structure of 1,3-diphenyl-2-propen-1-one, belong to the flavonoids family and are widespread in plants. Naturally occurring and synthetic chalcones are associated with several biological activities such as antioxidant, antiinflammatory, antibacterial, ant hyperglycemic, antifungal, antimalarial, anticancer, etc. [4].

An interesting family of chalcones is the furan based chalcones or furanochalcones [5], which are produced by the Claisen-Schmidt condensation between furfural derivatives and acetophenones. These compounds exhibit a variety of biological activities such as antiproliferative activity on breast cancer cells [6], antimicrobial activity [7], antileishmanial activity [8], antifungical [9], nitrification inhibitors [10] and some of them are used in the treatment of neoplasic diseases as cytotoxic drugs [11] and in neurodegenerative disorders such as Alzheimer's and Parkinson's [12]. More specifically, furanochalcones derivatives produced from HMF and acetophenones show activities in the treatment of pancreatic cancer [13] and breast cancer [14].

The most general method to obtain chalcones is by Claisen-Schmidt condensation between substituted acetophenones and substituted aromatic aldehydes using homogeneous basic catalysts such as aqueous or alcoholic alkali metal hydroxide solutions [4]. These homogeneous processes present drawbacks associated to the catalyst recovery, and the manufacturing process requires an additional step to neutralize the metal hydroxide, generally with $\mathrm{HCl}$, resulting in processes with a large $\mathrm{E}$ factor. These drawbacks can be avoided by using heterogeneous base catalyst, however the synthesis of furanochalcones are mainly based on the homogeneous method, being the use of heterogeneous catalysts really scarce. In this sense Yadav et al. [15] have recently reported the Claisen-Smidth condensation of furfural and acetophenone 
derivatives in the presence of $\mathrm{Al}_{2} \mathrm{O}_{3}$ on $\mathrm{CaO}$, achieving $98 \%$ yield of the corresponding furanochalcone.

However, and despite the pharmaceutical interest of HMF derived furanochalcones, the condensation of HMF with acetophenone derivatives has not been performed up to now using heterogeneous solid catalysts. Therefore, in this work, we have studied the Claisen-Schmidt condensation of HMF with acetophenones in the presence of different heterogeneous basic catalysts, and a series of furanochalcones derived from HMF have been obtained in high yields and selectivities, improving the results obtained with homogeneous catalysts.

\section{EXPERIMENTAL SECTION}

\section{Catalyst}

$\mathrm{Al} / \mathrm{Mg}$ hydrotalcite was prepared from gels produced by mixing two solutions: solution A containing $2.25 \mathrm{~mol}$ of $\mathrm{Mg}\left(\mathrm{NO}_{3}\right)_{2} \cdot 6 \mathrm{H}_{2} \mathrm{O}$ and $0.75 \mathrm{~mol}$ of $\mathrm{Al}\left(\mathrm{NO}_{3}\right)_{3} \cdot 9 \mathrm{H}_{2} \mathrm{O}$ in the $(\mathrm{Al}+\mathrm{Mg})$ concentration of $1.5 \mathrm{~mol} / \mathrm{L}$ for a molar ratio of 0.25 , the solution $\mathrm{B}$ containing of $6.75 \mathrm{~mol}$ of $\mathrm{NaOH}$ and $2 \mathrm{~mol}$ of $\mathrm{Na}_{2} \mathrm{CO}_{3}$ dissolved in the same volume of the solution A. Both solutions are co-added at a rate of $1 \mathrm{~mL} / \mathrm{min}$ under a vigorous mechanical stirring at room temperature. The suspension was left at $60{ }^{\circ} \mathrm{C}$ for $18 \mathrm{~h}$. The hydrotalcite formed was filtered and washed until the $\mathrm{pH}$ of the filtrate was 7 . The resultant solid was dried at $60{ }^{\circ} \mathrm{C}$ for $12 \mathrm{~h}$. The hydrotalcite was transformed in an $\mathrm{Al} / \mathrm{Mg}$ mixed oxide by calcination at $450{ }^{\circ} \mathrm{C}$ in a dry nitrogen flow. The temperature was raised at a rate of $2{ }^{\circ} \mathrm{C} / \mathrm{min}$ to reach $450{ }^{\circ} \mathrm{C}$ and was maintained at this temperature for $6 \mathrm{~h}$. The solid was then cooled until room temperature and used in reaction (labeled as $\mathrm{HTc})$. 
Rehydrated hydrotalcite (HTr) was obtained by rehydration of the calcined sample ( $\mathrm{HTc}$ ) by directly adding $36 \mathrm{wt} \%$ of $\mathrm{CO}_{2}$ free water on the $\mathrm{HTc}$ just before reaction [16]. A $\mathrm{MgO}$ sample with crystallite size of $3 \mathrm{~nm}$ and $670 \mathrm{~m}^{2} / \mathrm{g}$ surface area was purchased from NanoScale Materials and was calcined at $450{ }^{\circ} \mathrm{C}$ for $8 \mathrm{~h}$ first in air and finally in a stream of nitrogen to remove absorbed impurities and carbonates.

X-ray diffraction measurements were recorded with a Philips X'PERT (PN 3719) diffractometer $(\mathrm{Cu}-\mathrm{K} \alpha$ radiation provided by a graphite monochromator) equipped with an automatic variable divergence slit and working in the constant irradiated area mode. Data were collected stepwise over the $2^{\circ} \leq 2 \theta \leq 40^{\circ}$ angular region with steps of $0.02^{\circ}$ 20, a 20 s/step accumulation time, and $\mathrm{Cu} \operatorname{KR}(\lambda=1.54178 \AA$ A) radiation.

Chemical analyses of the samples were performed by atomic absorption after disintegration of the solids. $\mathrm{N}_{2}$ and Ar adsorption/desorption isotherms were performed at -196 and $-185.7^{\circ} \mathrm{C}$, respectively, in an ASAP 2010 apparatus from Micromeritics, after pre-treating the samples under vacuum at $400{ }^{\circ} \mathrm{C}$ overnight (for the calcined hydrotalcite) and at $120{ }^{\circ} \mathrm{C}$ (for the rehydrated hydrotalcite). The BET surfaces were obtained using the BET methodology. The physicochemical characteristics of the samples are summarized in Table 1.

Table 1. Physicochemical characteristics of the catalysts

\begin{tabular}{|c|c|c|c|c|}
\hline Catalyst & $\mathrm{Al} /(\mathrm{Al}+\mathrm{Mg})$ & $\begin{array}{c}\text { Surface area } \\
\mathrm{BET}\left(\mathrm{m}^{2} / \mathrm{g}\right)\end{array}$ & $\begin{array}{c}\text { Crystallite size } \\
(\mathrm{nm})\end{array}$ & $\begin{array}{c}\text { Average pore } \\
\text { diameter }(\AA)\end{array}$ \\
\hline $\mathrm{MgO}$ & - & 600 & 3 & $\mathrm{~nm}$ \\
\hline $\mathrm{HTr}$ & 0.25 & 25 & - & 277 \\
\hline $\mathrm{HTc}$ & 0.25 & 245 & $<50$ & 103 \\
\hline
\end{tabular}




\section{General Procedure for the Synthesis of Furanochalcones}

A mixture of 5-hydroxymethylfurfural (HMF) (1 mmol, $126 \mathrm{mg})$ and acetophenone (1 mmol, $120 \mathrm{mg}$ ), and solvent ( $2 \mathrm{~mL})$ was added to the catalyst and purged with nitrogen. The reaction mixture was vigorously stirred at $90{ }^{\circ} \mathrm{C}$. To check if the reaction was controlled by external diffusion, the condensation was by stirring the mixture of reactants at 500, 800 and $1000 \mathrm{rpm}$, and the results showed similar reaction rates when working at 800 and $1000 \mathrm{rpm}$, indicating that under these stirring speeds the reaction is not controlled by external diffusion. Therefore, the selected stirring speed for the catalytic experiments was $1000 \mathrm{rpm}$. At the end of the reaction, the catalyst was filtered off and washed successively with a mixture water/ethanol. After removing the solvent under reduced pressure, the furanochalcone was crystallized from ethanol.

In all reactions, samples were taken at regular intervals, diluted with ethanol, dried with anhydrous sodium sulfate and analyzed by gas chromatography (GC) equipped with a HP-5 column ( $30 \mathrm{~m} \times 0.25 \mathrm{~mm} \times 0.25 \mu \mathrm{m})$ and a FID as the detector, using nonane as external standard. In all cases the molar balance was $\geq 95 \%$.

The identification of the products was carried out by MS-GS (Agilent MDS-5973 with HP5 capillary column) and NMR spectroscopy with a Bruker Avance 300 spectrometer working at $300 \mathrm{MHz}$ for ${ }^{1} \mathrm{H}$ and $75 \mathrm{MHz}$ for ${ }^{13} \mathrm{C}$.

Recycling test of HTc

For catalyst recycling studies, the solid was collected by filtration, washed with water/ethanol and calcined at $450{ }^{\circ} \mathrm{C}$ for $7 \mathrm{~h}$ in air. 


\section{RESULTS AND DISCUSSION}

In order to find the most adequate solid base catalyst to perform the synthesis of furyl substituted chalcones, the Claisen-Schmidt condensation between HMF and acetophenone was taken as reaction model (Scheme 1).

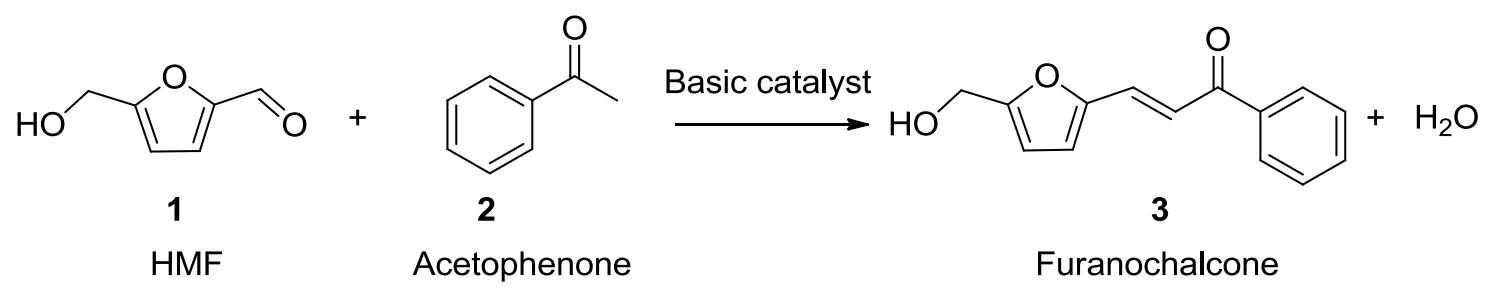

Scheme 1. Claisen-Schmidt condensation of HMF with acetophenone.

Under basic catalysis, and depending on the nature of the catalyst and reaction conditions different side reactions can also occur such as the self-condensation of acetophenone leading to the formation of dypnone, the Cannizzaro disproportion of the aldehyde that in the case of HMF affords 5-hydroxymethylfuranoic acid and 2,5dihydroxymethylfuran as by-products [17], while oligomerization reactions of the $\alpha-\beta$ unsaturated ketone can also take place. Therefore the optimization of the catalyst and reaction conditions is of paramount importance to achieve high selectivity to the furanochalcones.

To do that, we selected as catalysts different solids with basic sites able to abstract the proton in the methyl group of acetophenone, such as a high surface area $\mathrm{MgO}$, an $\mathrm{Al} / \mathrm{Mg}$ mixed oxide $(\mathrm{HTc})$ produced from calcination of an $\mathrm{Al} / \mathrm{Mg}$ hydrotalcite, and a rehydrated $\mathrm{Al} / \mathrm{Mg}$ mixed oxide $(\mathrm{HTr})$.

$\mathrm{MgO}$ and $\mathrm{Al} / \mathrm{Mg}$ mixed oxides have strong Lewis basicity associated to $\mathrm{O}^{2-} \mathrm{M}^{+2}$ ion pairs [18] that have shown excellent activity for aldol condensations including the 
Claisen-Schmidt condensation [19,20,21,22,23,24,25]. Moreover, it is known that the hydration of the $\mathrm{Al} / \mathrm{Mg}$ mixed oxide with $\mathrm{CO}_{2}$ free water lead to the partial restoration of the layered structure of the hydrotalcite in which some of the $\mathrm{CO}_{3}{ }^{2-}$ compensation anions in the interlayer space are replaced by $\mathrm{OH}^{-}$anions which operate as strong Bronsted basic sites $[26,27,28]$ able to perform a variety of aldol type condensations $[16,26,29,30]$.

The catalytic activity of these materials was tested in the Claisen-Schmidt condensation of acetophenone and $\mathrm{HMF}$ at $90{ }^{\circ} \mathrm{C}$ in the presence of $15 \mathrm{wt} \%$ of catalyst and in absence of solvent. In Table 2 are presented the results obtained for each catalyst. In the three cases the only product detected was the corresponding chalcone ((E)-3-(5(hydroxymethyl)furan-2-yl)-1-phenylprop-2-en-1-one)(3), while in absence of catalyst no product was detected (Table 2). As can be observed in Table 2, the $\mathrm{MgO}$ was the most active catalyst, being the order of activity measured as per the initial reaction rate: $\mathrm{MgO}>\mathrm{HTr}>\mathrm{HTc}$. The higher activity exhibited by the high surface area MgO compared with HTc and HTr can be attributed to the higher concentration of strong basic sites in this sample. Since the aldol condensation is a reaction sensitive to the structure [25], the very small crystallites $(3 \mathrm{~nm})$ of the $\mathrm{MgO}$ sample used presents a high ratio of atoms located at corners and steps of the crystallites, and these have been associated to the presence of stronger basic oxygen sites in $\mathrm{MgO}$ [31]. Nevertheless, if one calculates the intrinsic activity of each catalyst by dividing the initial reaction rate per surface area unit (Table 2), the highest specific activity corresponds to $\mathrm{HTr}$ sample bearing Bronsted basic sites associated to $\mathrm{OH}^{-}$which are formed during the rehydration. In other words, it is clear that Bronsted basicity works much better than Lewis basicity present on the catalysts studied for the condensation reaction between acetophenone and HMF. 
On the other hand, it should be noted that the reaction stops before reaching full conversion on the three solid catalysts. This would be an indication that a deactivation of the catalyst occurs. The deactivation of the catalysts can be attributed to a strong adsorption of reactants and/or products on the catalyst surface. Then, the catalysts were recovered after use and extracted in a Soxhlet apparatus using dichloromethane as a solvent, it was observed that the amounts of organic material retained on the surface were $0.88,2.73$ and $1.34 \mathrm{wt} \%$ (respect to the amount of catalyst) for $\mathrm{MgO}, \mathrm{HTr}$ and HTc respectively. The amount of organic extracted from each catalysts, as well as the products found in the extracts are summarized in Table 3. As can be observed there, the main component of the extracted products corresponds to $\mathrm{HMF}(95,56$ and $79 \mathrm{wt} \%$ for $\mathrm{MgO}, \mathrm{HTr}$ and $\mathrm{HTc}$ respectively). At the same time the amount of furanochalcone 3 that remains adsorbed on the catalyst is particularly significant in the case of HTc ( 15.9 wt \%) and $\mathrm{HTr}(28.8 \mathrm{wt} \%)$. Moreover, the TG analysis of the samples indicate that a considerable amount of organic material still remains strongly adsorbed on the catalysts after Soxhlet extraction, being $28.1 \%, 11.2 \%$ and $16.5 \%$ for $\mathrm{MgO}, \mathrm{HTc}$ and $\mathrm{HTr}$, respectively. Considering the composition of the organic extracts (Table 3) it appears that although the adsorption of furanochalcone contributes to catalyst decay (in the cases of HTc and HTr) the strong adsorption of HMF, is the main cause of deactivation of the catalysts in all cases. To avoid or at least decrease the deactivation of the catalysts due to the strong adsorption of HMF, we thought on using a solvent that can help to avoid complete surface coverage by HMF and the product. 
Table 2. Claisen-Schmidt condensation of acetophenone and HMF in absence of solvent using different heterogeneous basic catalysts. ${ }^{\text {a }}$

\begin{tabular}{lccccc}
\hline & $\mathrm{r}^{\mathrm{0}} 10^{5}$ & $\mathrm{r}^{\mathrm{0}} 10^{5}$ & Conv & Yield $(\%)$ & Selectivity \\
Catalyst & $\left(\mathrm{mol} \mathrm{min}^{-1} \mathrm{~g}^{-1}\right)$ & $\left(\mathrm{mol} \mathrm{min}^{-1} \mathrm{~m}^{-2}\right)$ & $\mathrm{HMF}$ & of $\mathbf{3}$ & $(\%)$ of $\mathbf{3}$ \\
& & & $(\%)$ & & \\
\hline Blank & - & - & - & - & - \\
$\mathrm{HTr}$ & 59.7 & 238.0 & 44 & 43 & 99 \\
$\mathrm{HTc}$ & 2.2 & 0.9 & 17 & 16 & 99 \\
$\mathrm{MgO}$ & 123.7 & 20.6 & 67 & 66 & 99 \\
\hline
\end{tabular}

${ }^{a}$ Reaction conditions: HMF ( $\left.1 \mathrm{mmol}\right)$, acetophenone $(1 \mathrm{mmol}), 15 \mathrm{wt} \%$ of catalyst at 90 ${ }^{\circ} \mathrm{C}, 5 \mathrm{~h}$, without solvent.

Table 3. Amount of extracted organic material and distribution of compounds in the organic for each used catalyst.

\begin{tabular}{|c|c|c|c|c|}
\hline \multirow[t]{3}{*}{ Catalyst } & \multirow{3}{*}{$\begin{array}{l}\text { Organic } \\
\text { material } \\
(\mathrm{wt} \%)^{\mathrm{a}}\end{array}$} & \multicolumn{3}{|c|}{ Distribution of compounds in the extracted organic } \\
\hline & & \multicolumn{3}{|c|}{ material (wt \%) } \\
\hline & & acetophenone & $\mathrm{HMF}$ & furanochalcone \\
\hline HTc & 1.3 & 5.0 & 79.1 & 15.9 \\
\hline $\mathrm{HTr}$ & 2.7 & 14.9 & 56.3 & 28.8 \\
\hline $\mathrm{MgO}$ & 0.8 & 1.8 & 95.8 & 2.4 \\
\hline
\end{tabular}

\section{Influence of the solvent}

The condensation between HMF and acetophenone was performed with two polar solvents with different dielectric constants that are able to solubilize both reactants (HMF and acetophenone). These solvent are acetonitrile, and ethanol, with dielectric constants $(\varepsilon)$ of 37 and 24 respectively. 
As can be observed in Table 4 in all catalysts, the highest initial activity is obtained with the most polar solvent and the order of reactivity is higher for the solvent with the higher dielectric constant: acetonitrile. A possible reason of these results can be based on differences on activation energy of the solvated transition states. If the reaction is performed with a polar solvent, the transition state complex could be better solvated decreasing the activation free enthalpy, enhancing the reaction rate as the solvent polarity is increased [32]. Moreover, it is observed that in the presence of polar solvents the order of activity (initial reaction rates) of the catalysts changes with respect to the results obtained when the reaction was performed in absence of solvent (see Table 2), being $\mathrm{HTr}>\mathrm{MgO}>\mathrm{HTc}$. In other words, it appears that the most " anionic" transition state, which should be formed on the strongest Bronsted basic sites present in HTr sample will be further stabilized, giving therefore the highest reaction rate.

On the other hand, the presence of solvent has not decreased the extent of catalyst deactivation and again the extraction of the used catalysts with dichloromethane in a Soxhlet apparatus showed that also when using solvent the extract is mainly composed of $\mathrm{HMF}$ and furanochalcone $\mathbf{3}$, being the HMF the main component. This confirms that the main cause of catalyst deactivation is the strong adsorption of these compounds. The strong adsorption of the HMF and furanochalcone on the catalyst surface could be attributed to the presence in their structure of weakly acidic hydroxymethyl group that can strongly interact with the basic sites. In order to check that, the reaction was performed using furfural that unlike HMF, has not a hydroxymetyl group in the molecule. HTr was used as catalyst and ethanol as solvent. As can be observed in Figure 1, very good results were obtained in this case achieving $100 \%$ yield after $6 \mathrm{~h}$ of reaction, and the amount of furfural adsorbed $(<1 \%$ wt $\%)$ was sensibly lower than HMF. 
Table 4. Influence of the solvent in the condensation of HMF and acetophenone using $\mathrm{MgO}, \mathrm{HTr}$ and HTc as catalyst. ${ }^{\mathrm{a}}$

\begin{tabular}{|c|c|c|c|c|c|c|c|}
\hline Entry & Catalyst & Solvent & 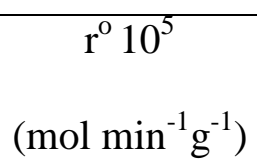 & $\begin{array}{l}\text { Time } \\
\text { (h) }\end{array}$ & $\begin{array}{c}\text { Conv. (\%) } \\
\text { HMF }\end{array}$ & $\begin{array}{c}\text { Yield (\%) } \\
\text { of } \mathbf{3}\end{array}$ & $\begin{array}{c}\text { Selec }(\%) \\
\text { of } \mathbf{3}\end{array}$ \\
\hline 1 & $\mathrm{MgO}$ & $\mathrm{EtOH}$ & 11.6 & $\begin{array}{c}4 \\
24\end{array}$ & $\begin{array}{l}35 \\
54\end{array}$ & $\begin{array}{l}30 \\
45\end{array}$ & $\begin{array}{l}86 \\
83\end{array}$ \\
\hline 2 & $\mathrm{MgO}$ & $\mathrm{ACN}$ & 14.7 & $\begin{array}{c}4 \\
24\end{array}$ & $\begin{array}{l}34 \\
49\end{array}$ & $\begin{array}{l}33 \\
47\end{array}$ & $\begin{array}{l}97 \\
96\end{array}$ \\
\hline 3 & $\mathrm{HTr}$ & $\mathrm{EtOH}$ & 22.2 & $\begin{array}{c}4 \\
24\end{array}$ & $\begin{array}{l}39 \\
50\end{array}$ & $\begin{array}{l}38 \\
49\end{array}$ & $\begin{array}{l}99 \\
98\end{array}$ \\
\hline & & & & 0.25 & 36 & 36 & 99 \\
\hline 4 & $\mathrm{HTr}$ & $\mathrm{ACN}$ & 73.5 & $\begin{array}{c}4 \\
24\end{array}$ & $\begin{array}{l}55 \\
61\end{array}$ & $\begin{array}{l}54 \\
60\end{array}$ & $\begin{array}{l}99 \\
98\end{array}$ \\
\hline 5 & HTc & $\mathrm{EtOH}$ & 4.9 & $\begin{array}{c}4 \\
24\end{array}$ & $\begin{array}{l}12 \\
18\end{array}$ & $\begin{array}{l}12 \\
18\end{array}$ & $\begin{array}{l}100 \\
100\end{array}$ \\
\hline 6 & HTc & $\mathrm{ACN}$ & 10.2 & $\begin{array}{c}4 \\
24\end{array}$ & $\begin{array}{l}13 \\
17\end{array}$ & $\begin{array}{l}13 \\
17\end{array}$ & $\begin{array}{l}100 \\
100\end{array}$ \\
\hline
\end{tabular}

${ }^{\mathrm{a}}$ Reaction conditions: HMF (1 mmol), acetophenone $(1 \mathrm{mmol})$, solvent $(2 \mathrm{~mL})$, Catalyst $15 \mathrm{wt} \%$ with respect to the mass of reactants, at $90{ }^{\circ} \mathrm{C}$. 


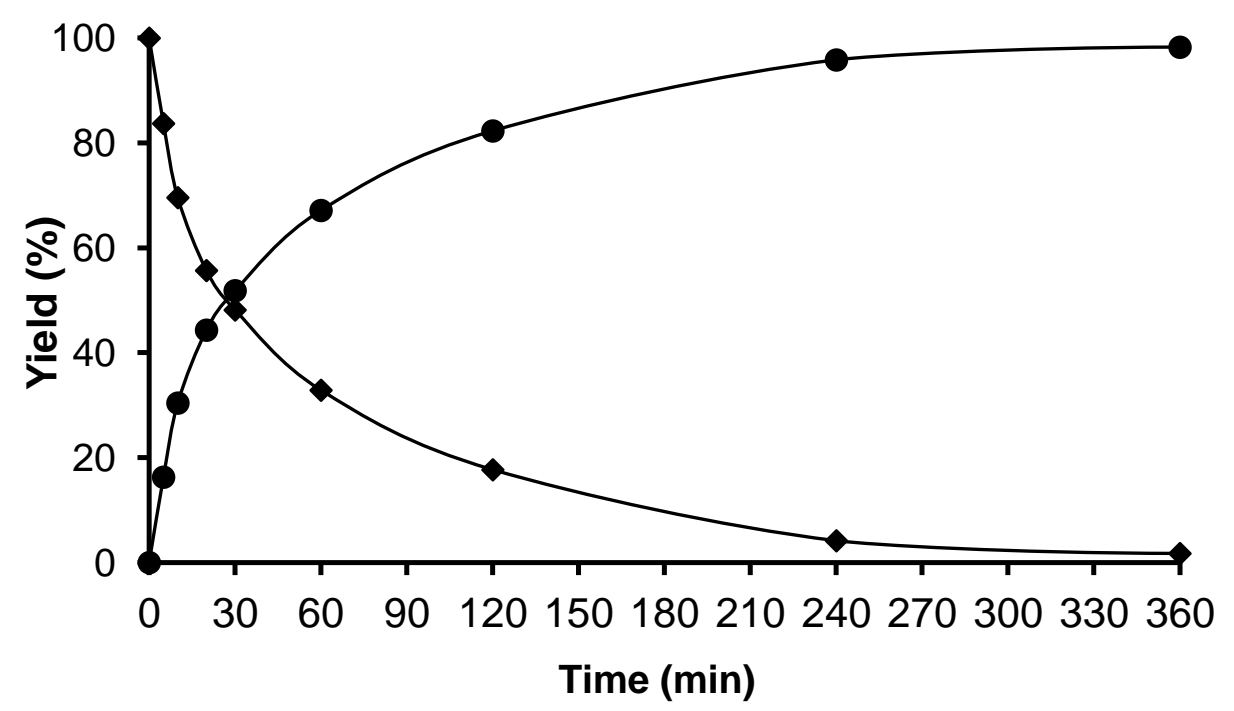

Figure 1. Claisen- Schmidt condensation of furfural and acetophenone. Reaction conditions: furfural $(1 \mathrm{mmol})$, acetophenone $(1 \mathrm{mmol})$, ethanol $(2 \mathrm{~mL})$; Catalyst: HTr $\left(15 \mathrm{wt} \%\right.$ respect to the total amount of reactants), at $90{ }^{\circ} \mathrm{C}$. furfural $(\bullet)$, chalcone $(\bullet)$.

On these bases, the polarity of the solvent has been further increased by working with mixtures of ethanol-water. Thus, when the reaction was performed with the three catalysts (Table 5) using mixtures of ethanol-water $(1 \mathrm{~mL}: 1 \mathrm{~mL})$ as a solvent, a considerable increase of the initial reaction rate with respect to the values obtained before with ethanol is observed, showing again the benefit of increasing the solvent polarity. Gratifyingly, the catalyst decay was considerably depressed with HTr and HTc catalysts, achieving in both cases practically total conversion of HMF with $100 \%$ selectivity to chalcone $\mathbf{3}$ after $4 \mathrm{~h}$ reaction time. These results would indicate that, the presence of water limits the strong adsorption of $\mathrm{HMF}$ and furanochalcone on the catalyst surface, decreasing the deactivation rate of the catalyst. Indeed, the amount of HMF and furanochalcone that remains adsorbed on those two catalysts is now clearly lower (0.9 and 1.6 wt \% for HTc and HTr respectively, instead of 1.7 wt \% 3.2 when using ethanol as solvent). Notice that in the case of HTc water works as both solvent and rehydrating agent. Thus, the increase in activity of HTc when a mixture of ethanol- 
water is used, besides the positive effect of the polarity of the solvent, the in situ rehydration of the HTc that generates $\mathrm{HTr}$ (see the XRD of the used catalyst in Figure 2) can also play a positive role on the activity of the HTc sample.

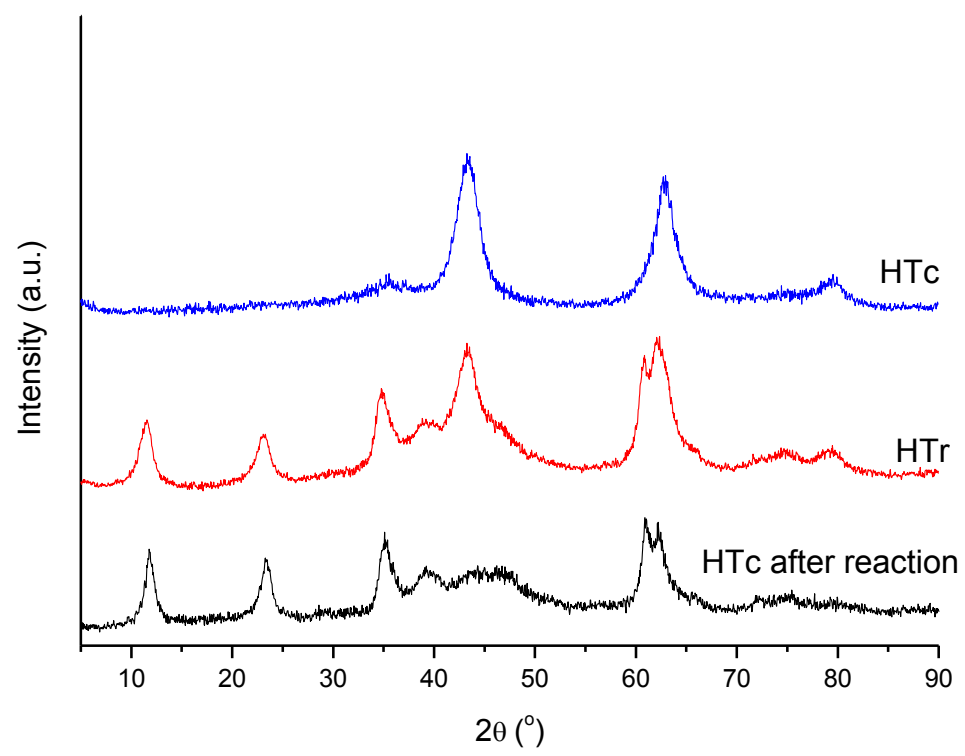

Figure 2. Powder X-ray diffraction (XRD) patterns of the fresh HTc, HTr and HTc after reaction in the Claisen-Schmidt condensation of HMF and acetophenone using ethanolwater as a solvent.

On the contrary, in the case of $\mathrm{MgO}$ a strong deactivation of the catalyst is observed with the ethanol-water mixture, since conversion of HMF does not surpass $39 \%$ after $24 \mathrm{~h}$ of reaction time. In this case, the deactivation can be mainly attributed to structural changes on $\mathrm{MgO}$ that is in situ rehydrated into $\mathrm{Mg}(\mathrm{OH})_{2}$ during the reaction, and which posses negligible catalytic activity for aldol condensations compared with rehydrated $\mathrm{Al} / \mathrm{Mg}$ mixed oxides [33]. In fact, the XRD of the used $\mathrm{MgO}$ catalyst (see Figure 3) showed the typical difractogram of the $\mathrm{Mg}(\mathrm{OH})_{2}$, with characteristics peaks (XRD) of $\mathrm{Mg}(\mathrm{OH})_{2}$ with $2 \theta$ values of : $18.4,38.0,50.9,58.7,62.2,68.4,72.1$. 


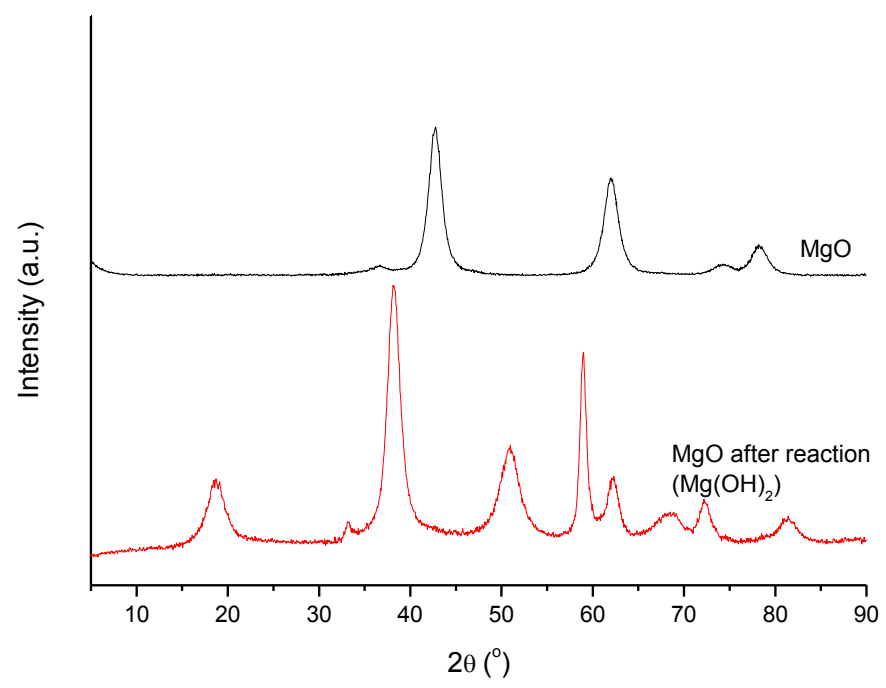

Figure 3. Powder X-ray diffraction (XRD) patterns of $\mathrm{MgO}$ before and after use in the Claisen-Schmidt condensation of HMF and acetophenone using ethanol-water.

Table 5. Claisen- Schmidt condensation of HMF and acetophenone using ethanol-water as a solvent in the presence of $\mathrm{MgO}, \mathrm{HTr}$ and HTc catalysts. ${ }^{\mathrm{a}}$

\begin{tabular}{|c|c|c|c|c|c|c|}
\hline Entry & Catalyst & $\begin{array}{c}\mathrm{r}^{\mathrm{o}} 10^{5} \\
\left(\mathrm{~mol} \mathrm{~min} \mathrm{~m}^{-1} \mathrm{~g}^{-1}\right)\end{array}$ & $\begin{array}{l}\text { Time } \\
\text { (h) }\end{array}$ & $\begin{array}{c}\text { Conv.(\%) } \\
\text { HMF }\end{array}$ & $\begin{array}{c}\text { Yield (\%) } \\
\text { of } \mathbf{3}\end{array}$ & $\begin{array}{c}\text { Selec (\%) } \\
\text { of } \mathbf{3}\end{array}$ \\
\hline \multirow{3}{*}{1} & \multirow{3}{*}{$\mathrm{MgO}$} & \multirow{3}{*}{21.0} & 4 & 36 & 34 & 94 \\
\hline & & & 24 & 39 & 37 & 95 \\
\hline & & & 0.17 & 39 & 39 & 100 \\
\hline \multirow[t]{2}{*}{2} & \multirow[t]{2}{*}{$\mathrm{HTr}$} & \multirow[t]{2}{*}{106.2} & 4 & 96 & 96 & 100 \\
\hline & & & 24 & 99 & 99 & 100 \\
\hline \multirow[b]{2}{*}{3} & \multirow[b]{2}{*}{ HTc } & \multirow{2}{*}{46.3} & 0.33 & 40 & 40 & 100 \\
\hline & & & 4 & 99 & 99 & 100 \\
\hline 4 & $\mathrm{NaOH}^{\mathrm{b}}$ & 483.6 & 1 & 95 & 75 & 75 \\
\hline
\end{tabular}

${ }^{a}$ Reaction conditions: HMF (1 mmol), acetophenone $(1 \mathrm{mmol})$; Catalyst $15 \mathrm{wt} \%$ with respect to the mass of reactants, at $90{ }^{\circ} \mathrm{C}$. Solvent: $1 \mathrm{~mL}$ ethanol plus $1 \mathrm{~mL}$ water. ${ }^{\mathrm{b}}$ The reaction was performed using $\mathrm{NaOH}$ ( $4 \mathrm{wt} \%$ respect to the mass of reactants) in $1 \mathrm{~mL}$ ethanol plus $1 \mathrm{~mL}$ water at room temperature. 
For comparison purposes, the reaction was performed using as homogeneous base an aqueous-ethanolic solution ( $1 \mathrm{~mL}$ ethanol-1 $\mathrm{mL} \mathrm{H}_{2} \mathrm{O}$ ) and $\mathrm{NaOH}(4 \mathrm{wt} \%$ with respect to the mass of reactants) (Table 5, entry 4). $95 \%$ conversion of HMF was achieved but only $75 \%$ yield of furanochalcone (3). The lack of selectivity in this case is consistent with the presence of products coming from the Cannizzaro disproportion of HMF and polymerization. These results are similar to those previously reported in the patent literature for the condensation of HMF and acetophenone at room temperature using an ethanolic solution of $\mathrm{NaOH}$ [14]. It appears then that either the HTc or HTr catalysts studied here are clearly superior in terms of yield and selectivity to furanochalcone $\mathbf{3}$, to the conventional homogeneous process.

The effect of the water on the initial reaction rate and catalyst decay was confirmed by doing the reaction using mixtures of water with different polar solvents (methanol, acetonitrile and isopropanol) using HTc as catalyst. As can be observed in Table 6, good results were achieved in all cases, being ethanol-water mixture the best solvent in terms of HMF conversion and furanochalcone yields. 
Table 6. Claisen- Schmidt condensation of HMF and acetophenone using as a solvent different mixtures of organic solvent-water in the presence of HTc catalysts ${ }^{\mathrm{a}}$.

\begin{tabular}{lcccc}
\hline \multicolumn{1}{c}{ Solvent } & $\mathrm{r}^{\mathrm{o}} 10^{5}$ & Conv (\%) HMF & Yield (\%) & Selec (\%) \\
& $\left(\mathrm{mol} \mathrm{min}^{-1} \mathrm{~g}^{-1}\right)$ & & of $\mathbf{3}$ & of $\mathbf{3}$ \\
& & & & \\
\hline Methanol $/ \mathrm{H}_{2} \mathrm{O}$ & 98.0 & 94 & 90 & 95 \\
Ethanol/ $\mathrm{H}_{2} \mathrm{O}$ & 46.3 & 99 & 99 & 100 \\
Isopropanol/ $\mathrm{H}_{2} \mathrm{O}$ & 76.9 & 93 & 88 & 94 \\
ACN/ $\mathrm{H}_{2} \mathrm{O}$ & 62.5 & 84 & 82 & 98
\end{tabular}

\footnotetext{
${ }^{a}$ Reaction conditions: HMF ( $\left.1 \mathrm{mmol}\right)$, acetophenone $(1 \mathrm{mmol})$, solvent $(1 \mathrm{~mL}$ organic solvent plus $1 \mathrm{~mL}$ of water), $15 \mathrm{wt} \% \mathrm{HTc}$ respect to the total amount of reactants, temperature $90{ }^{\circ} \mathrm{C}, 4 \mathrm{~h}$.
}

\section{Catalyst reusability}

For reducing the cost and environmental impact of the process, an important advantage of using heterogeneous catalysis is that the catalyst can be easily recovered by filtration and reused. In order to study the reusability of HTc, after a first cycle of reaction using ethanol-water as a solvent, the catalyst was filtered off, thoroughly extracted with dichloromethane in a Soxhlet apparatus and used in a second cycle under the same reaction conditions. However, only $16 \%$ conversion of $\mathrm{HMF}$ was observed after $24 \mathrm{~h}$, indicating that the catalyst is strongly deactivated during the first cycle. The analysis of the organic extracted by Soxhlet $(0.9 \mathrm{wt} \%)$ of the used catalyst showed that it was mainly composed by furanochalcone $(70 \mathrm{wt} \%)$ indicating that this compound is the main poison on the catalyst, being the cause of deactivation. IR analysis of the used catalyst (Figure 4) showed a increased adsorption band around $1643 \mathrm{~cm}^{-1}$ which can be attributed to the carbonyl group of the furanochalcone. Thus, in order to regenerate the catalytic activity of the solid, after their use, the adsorbed organic material was removed 
by calcination of the catalyst at $450{ }^{\circ} \mathrm{C}$, and applying this protocol, the catalyst could be recycled up to four consecutive cycles without any significant loss of activity (Figure $5)$.

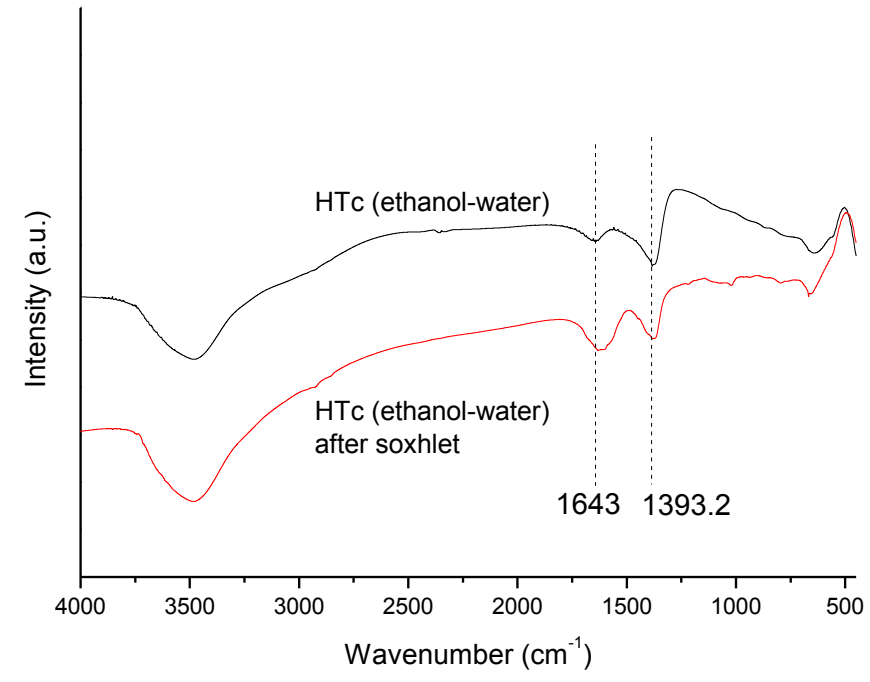

Figure 4. IR spectra of HTc (ethanol-water) before and after use in the Claisen- Schmidt condensation of HMF and acetophenone using ethanol-water.

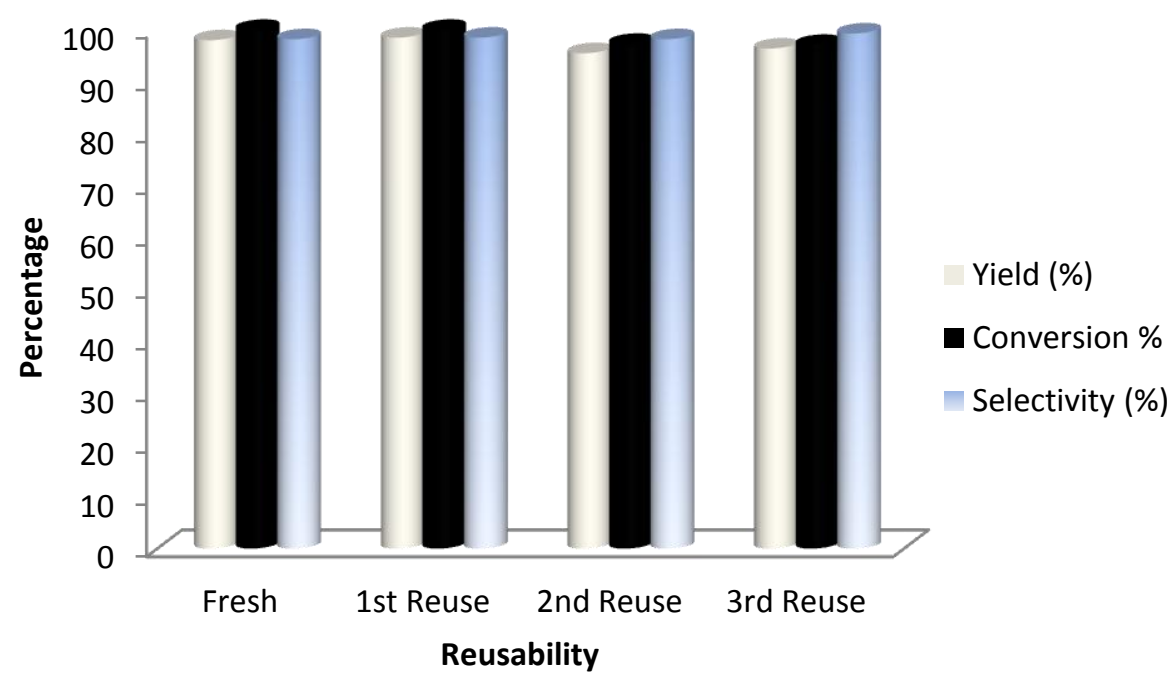


Figure 5. Reusability of catalyst. Reaction conditions: HMF (1 mmol, $126 \mathrm{mg}$ ), acetophenone (1 mmol, $120 \mathrm{mg}), 15 \mathrm{wt} \% \mathrm{HTc}$ with respect the total amount of reactants, solvent EtOH: $\mathrm{H}_{2} \mathrm{O}(1 \mathrm{~mL}: 1 \mathrm{~mL})$, temperature $90{ }^{\circ} \mathrm{C}, 4 \mathrm{~h}$

\section{Scope of the reaction}

HTc in ethanol-water as a solvent was used to perform the Claisen-Smidth condensation of various $p$-substituted acetophenones and furfuraldehydes derivatives (HMF, furfural and 5-methylfurfural). As can be observed in Table 7, good conversion and selectivities to the corresponding furanochalcones derivatives were obtained in all cases.

Table 7. Synthesis of furanochalcones using HTc as catalyst ${ }^{\mathrm{a}}$.

\begin{tabular}{lcccc}
\hline Acetophenone & Aldehyde & Furanochalcone & Yield & Selec \\
& & $(\%)$ & $(\%)$ \\
\hline & & & &
\end{tabular}

3<smiles>CC(=O)c1ccc(C)cc1</smiles>

HMF<smiles>Cc1ccc(C(=O)/C=C/c2ccc(CO)o2)cc1</smiles>

$86(8 \mathrm{~h}) \quad 99$

3a

$93(24 \mathrm{~h}) \quad 99$<smiles>COc1ccc(C(C)=O)cc1</smiles>

HMF<smiles>COc1ccc(C(=O)/C=C/c2ccc(CO)o2)cc1</smiles>

3b<smiles>CC(=O)c1ccc(Cl)cc1</smiles>

HMF<smiles>O=C(/C=C/c1ccc(CO)o1)c1ccc(Cl)cc1</smiles> 
<smiles>CC(=O)c1ccc(Br)cc1</smiles>

HMF<smiles>O=C(/C=C/c1ccc(CO)o1)c1ccc(Br)cc1</smiles>

3d<smiles>CC(=O)c1ccc([N+](=O)[O-])cc1</smiles>

HMF<smiles>O=C(/C=C/c1ccc(CO)o1)c1ccc([N+](=O)[O-])cc1</smiles>

$83(8 \mathrm{~h}) \quad 95$

$3 e$<smiles>CC(=O)c1ccc(N)cc1</smiles>

HMF<smiles>Nc1ccc(C(=O)/C=C/c2ccc(CO)o2)cc1</smiles>

3f

Nom

HMF<smiles>CC1=CCCC(C)(C)C1/C=C/C(=O)/C=C/c1ccc(CO)o1</smiles>

$70(6 \mathrm{~h}) \quad 98$ $82(20 \mathrm{~h}) \quad 99$

$3 g$ $83(10 \mathrm{~h})^{\mathrm{b}} \quad 99$ $93(22 \mathrm{~h})^{\mathrm{b}} \quad 99$<smiles>COc1cc(C(C)=O)cc(OC)c1OC</smiles>

HMF<smiles>COc1cc(C(=O)/C=C/c2ccc(CO)o2)cc(OC)c1OC</smiles>
$83(8 \mathrm{~h}) \quad 99$ $94(24 \mathrm{~h}) \quad 99$

$3 h$<smiles>CC(=O)c1ccccc1</smiles>

Furfural<smiles>O=C(/C=C/c1ccco1)c1ccccc1</smiles>
$100(6 \mathrm{~h}) \quad 100$

$3 \mathbf{i}$<smiles>CC(=O)c1ccccc1</smiles>

methylfurfural<smiles>Cc1ccc(/C=C/C(=O)c2ccccc2)o1</smiles>
$93(6 \mathrm{~h}) \quad 99$ $99(20 \mathrm{~h}) \quad 99$ 
${ }^{a}$ Reaction conditions: aldehyde ( $\left.1 \mathrm{mmol}\right)$, substituted acetophenone ( $\left.1 \mathrm{mmol}\right), 15 \mathrm{wt} \%$ HTc respect to amount of reactants, solvent EtOH: $\mathrm{H}_{2} \mathrm{O}(1 \mathrm{~mL}: 1 \mathrm{~mL})$, at $90{ }^{\circ} \mathrm{C}$. ${ }^{\mathrm{b}}$ at 110 ${ }^{\circ} \mathrm{C}$.

\section{CONCLUSIONS}

We have seen that HMF can react with different acetophenones using HTc, HTr and $\mathrm{MgO}$ as solid basic catalysts. The three catalysts can give high selectivity in absence of solvent, but unlike furfural, catalysts become rapidly deactivated. The deactivation is due to the strong adsorption of HMF and the furanochalcone obtained. Introducing polar solvents in the reaction do not allow increasing HMF conversion while important catalyst decay still occurs. A further increase in polarity by using a mixture ethanolwater allows finally obtaining high conversion and high selectivity to furanochalcone. While the activity of the homogeneous $\mathrm{NaOH}$ catalyst is higher than that of the solid catalyst the selectivity of the later is clearly better. It appears that the active phase of the calcined hydrotalcite in the ethanol-water medium corresponds to a partially restored hydrotalcite with basic hydroxyl groups. This is formed by the transformation of the mixed oxide fraction generated by calcinations at $450{ }^{\circ} \mathrm{C}$, when it was contacted with water. The calcined hydrotalcite allows a wide reaction scope when working in ethanol-water as a solvent. After use, the HTc catalyst was regenerated by calcination at $450{ }^{\circ} \mathrm{C}$, maintaining their catalytic activity through four consecutive runs.

\section{ACKNOWLEDGEMENTS}

Financial support by Consolider-Ingenio 2010 (project MULTICAT), Generalitat Valenciana (Prometeo program) and Program Severo Ochoa are gratefully acknowledged. 


\section{REFERENCES}

[1] a) Werpy T, Petersen GR (2004) Top Value Added Chemicals from Biomass.

Volume I. Results of Screening for Potential Candidates from Sugars and Synthesis Gas, U.S.D. Energy; b) Bozell JJ, Petersen GR (2010) Green Chem 12:539-554

[2] a) Climent MJ, Corma A, Iborra S (2011) Green Chem 13:520-540; b) Esposito D, Antonietti M (2015) Chem Soc Rev 44: 5821-5835

[3] a) Rosatella AA., Simeonov SP, Frade, RFM.; Afonso CAM (2011) Green Chem 13:754-793; b) van Putten RJ, van der Waaal JC, de Jong E, Rasrendra CB, Heeres HJ, de Vries JG (2013) Chem Rev 113:1499-1597

[4] a) Dhar, DH (1981) The Chemistry of Chalcones and Related Compounds. J. Wiley and Sons, New York; b) Ghosh R, Das A (2014) World J Pharm Pharm Sci 3: 578-595;

c) Suwito HJM, Kristanti AN, Tri P, Ni N (2014) J Chem Pharm Res 6:1076-1088

[5] Shaikh SB, Mujahid S, Tambat N, Salgar K, Nimbale RV (2014) Int J Pharm Res Schol 3:317-329

[6] Solomon VR, Lee H (2012) Biomed Pharmacother 66: 213-220

[7] Ahmet O, Mehlika DA, Zerrin C, Zafer AK (2015) Lett Drug Des Discov 12:607611

[8] Boeck P, Falcao C, Alves B, Leal PC, Yunes RA, Cechinel Filho V, Torres-Santos EC, Rossi-Bergmann B (2006) Bioorg Med Chem 14:1538-1545

[9] Jin H, Geng Y, Yu Z, Tao K, Hou T (2009) Pestic Biochem Physiol 93:133-137

[10] Datta A, Walia S, Parmar BS (2001) J Agric Food Chem 49: 4726-4731

[11] Konieczny M, Skladanowski A, Lemke K, Pieczykolan J (2011) WO 2011009826

[12] Robinson SJ, Petzer JP, Petzer A, Bergh JJ, Lourens, ACU (2013) Bioorg Med Chem Lett 23:4985-4989 
[13] a)Seth D, Hartman RF (2007), US 20070265317; b) Seth D, Hartman RF (2013) US 8552066

[14] Quincoces Suarez J, Peseke K, Molina Ruiz R (2006) EP1764363.

[15] Yadav GD, Yadav AR (2014) RSC Adv 4:63772-63778.

[16] Climent MJ, Corma A, Iborra S, Velty A (2004) J Catal 221:474-482

[17] Subbiah S, Simeonov SP, Esperança JMSS, Rebelo LPN, Afonso CAM (2013) Green Chem 15:2849-2853

[18] a)Albertazzi S, Basile F, Vaccari A (2004) Inter SciTechnol 1:496-546; b) Aramendia M A, Borau V, Jimenez C, Marinas JM, Ruiz JR, Urbano FJ (2000) Mat Lett 46:309-314

[19] Climent MJ, Corma A, Iborra S, Marti L (2015) ACS Catalysis 5:157-166

[20] Climent MJ, Corma A, Iborra S, Primo J (1995) J Catal 151:60-66

[21] Guida A, Lhouty MH, Tichit D, Figueras F, Geneste P (1997) Appl Catal A: General 164:251-264

[22] Tichit D, Coq B (2003) Cattech 7:206-217

[23] Vaccari A, Zicmanis A (2004) Catal. Commun 5:145-150

[24] Climent MJ, Corma A, Iborra S, Epping K, Velty A (2004) J Catal 225:316-326

[25] Climent MJ, Corma A, Iborra S, Mifsud M (2007) J Catal 247:223-230

[26] Rao KK, Gravelle M, Valente J, Figueras F (1998) J Catal 173:115-121

[27] Tichit D, Lutic D, Coq B, Durand R, Teissier R (2003) J Catal 219:167-175

[28] Roelofs JCAA, Lendsveld DJ, van Dillen AJ, de Jong P (2001) J Catal 203:184191

[29] Climent MJ, Corma A, Iborra S, Velty A (2002) Green Chem 4:474-480

[30] Hora L, Kelbichova V, Kikhtyanin O, Bortnovskly O, Kubicka D (2014) Catal Today 223:138-147 
[31] Coluccia S, Tench AJ, Segall RL (1979) J Chem Soc, Faraday Trans 1: Physical Chemistry in Condensed Phases 75:1769-79

[32] Rodriguez I, Sastre G, Corma A, Iborra S (1999) J Catal 183:14-23

[33] Xu C, Gao Y, Liu X, Xin R, Wang Z (2013) RSC Adv 3:793-801 